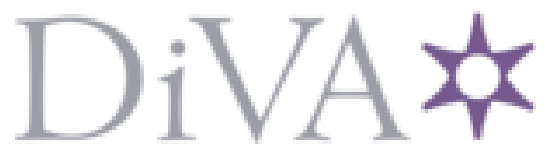

http://www.diva-portal.org

This is the published version of a paper presented at Conference paper-presented at the IRPA (International Radiological Protection Association) Conference 2018- June, den Hague.

Citation for the original published paper:

Döse, M., Silfwerbrand, J. (2018)

Supplementary Cementitious Materials and Additives - Effective Measures to Hinder Radon in Concrete

In: (pp. 8-). USA: Gudapuris

N.B. When citing this work, cite the original published paper.

Permanent link to this version:

http://urn.kb.se/resolve?urn=urn:nbn:se:kth:diva-233816 


\title{
Journal of Advanced Engineering
}

\author{
Research Article
}

\section{Supplementary Cementitious Materials and Additives - Effective Measures to Hinder Radon in Concrete}

\section{Magnus Dose $^{1 *}$, Johan Silfwerbrand ${ }^{2}$}

1KTH Royal Institute of Technology/Research Institute of Sweden, SE-501 15 Borås, Sweden

${ }^{2}$ KTH Royal Institute of Technology, SE-100 44 Stockholm, Sweden

Received: 10 July, 2018; Accepted: 14 July, 2018; Published: 18 July, 2018

*Corresponding Author: Magnus Döse, KTH Royal Institute of Technology/Research Institute of Sweden, SE-501 15 Borås, Sweden. E-mail: magnus.dose@ri.se

Copyright: (C) 2018 Dose M, Silfwerbrand J. Supplementary cementitious materials and additives- Effective measures to hinder radon in concrete. J Adv Eng; 1(2): 1-8.

\begin{abstract}
The second largest cause of lung cancer is related to radon $\left({ }^{222} \mathrm{Rn}\right)$ and its progenies in our environment. Building materials, such as concrete, contribute to the production of radon gas through the natural decay of ${ }^{238} \mathrm{U}$ from its constituents. The Swedish Cement and Concrete Research Institute (CBI) has examined ten different concrete recipes containing an additive or Supplementary Cementious Material (SCM), such as fly ash, slag or silica and combinations thereof. The SCM's were added in small to moderate portions and substituted the reference Portland cement (OPC). The inputs of an additive as well as a supplementary cementitious material were made as a mean to investigate their potential influence on the radon exhalation rates of the concrete as well as the radon gas diffusion length (L) that could be expected from the different recipes. Measurements were performed with an ATMOS 33 ionizing pulsation chamber. The results indicate a reduction of the exhalation rate by approximately $10-55 \%$ depending on recipe at an $\mathrm{RH}$ of $75 \%$. The diffusion coefficients, corrected for background subtraction vary in the interval $1.1 \times 10^{-10}-7.6 \times 10^{-12} \mathrm{~m} / \mathrm{s}^{2}$. The diffusion lengths vary between 2 and $9 \mathrm{~mm}$. In the case where the largest reduction of the exhalation rate is achieved, this roughly correspond to $>2 \mathrm{mSv}$ per year decrease in effective dose to a human. Consequently, using an additive or a SCM, as part of the mix, would be an option to effectively lower the radon gas exhalation in their initial stage of production. Secondly, the use of additives and SCM's will contribute to a lower environmental impact $\left(\mathrm{CO}_{2}\right)$.
\end{abstract}

Keywords: Radon; Effective Dose; Building Materials, Radon Gas Diffusion Length; Additives

\section{Introduction and Background}

Ionizing radiation and health

The second largest cause of lung cancer is ionizing radiation generated by radon and its progenies [1]. Building materials, such as concrete, contribute to the production of radon gas through the natural decay of $238 \mathrm{U}$ from its constituents. In Sweden mostly crushed bedrock is used as aggregate in concrete. The Swedish Cement and Concrete Research Institute (RISE CBI) has examined the use of liquid 
Dose M, Silfwerbrand J (2018) Supplementary cementitious materials and additives- Effective measures to hinder radon in concrete. J Adv Eng; 1(2): 107.

additives and supplementary cementitious materials (SCM's) and their effect on reducing the radon exhalation rate at an expected relative humidity of $75 \%$ measured ten millimeters into different concretes. Ten different concrete recipes were cast including one reference concrete. The diffusion coefficients of each concrete recipe were also examined. In this study the SCM's consisted of different fly ashes, micro silica and slag. All recipes contained identical aggregates and the water binder ratio $(\mathrm{w} / \mathrm{b})$ was set to 0.55 . The efficiency factor (k) was set to 1 for all SCM's.

\section{Methodology}

\section{Radon exhalation rate and radon gas measurements}

The measuring principle uses a "closed system with radon samples enclosed". As radon from the concrete product builds up within a sealed aluminum container a measure of the radon exhalation rate could be calculated for the first 24 hours. The codes adopted are defined in ISO Standard 11665-7 [2]. The radon gas exhalation rate $E\left(B q / \mathrm{m}^{2} \mathrm{~h}\right)$ is calculated knowing the initial conditions of the radon gas concentration in a "closed system" and within this project the linear regression model has been applied. The equation for the linear regression model can be described as:

$$
\mathrm{E}=\frac{\{(\mathrm{C}-\mathrm{Co}) \times \mathrm{V}\}}{\mathrm{A} \times \mathrm{t}}
$$

where: $\mathrm{E}=$ exhalation of radon gas $\left(\mathrm{Bq} / \mathrm{m}^{2} \mathrm{~h}\right), \mathrm{C}=$ concentration of radon gas measured by the radon gas monitor $\left(\mathrm{Bq} / \mathrm{m}^{3}\right), \mathrm{C}_{0}=$ background concentration of radon gas at initiation $\left(\mathrm{Bq} / \mathrm{m}^{3}\right), \mathrm{t}=$ time of duration (h), $A=$ effective surface area of the sample $\left(\mathrm{m}^{2}\right), V=$ volume of the container including hoses.

The Swedish Cement and Concrete Institute uses an ATMOS 33 semiconductor equipment developed by Gammadata $\mathrm{AB}$ (Figure 1a). The instrument uses an ionizing pulsation chamber that measures the alpha decay of ${ }^{218} \mathrm{Po}$. The decay of ${ }^{218} \mathrm{Po}$ has a distinct electric charge of $6 \mathrm{KeV}$ that could be counted and converted to ${ }^{222} \mathrm{Rn}$ knowing the decay rates of ${ }^{222} \mathrm{Rn}$ and ${ }^{218} \mathrm{Po}$.

Figure (1a): The Atmos 33 (Atmos 12DPX) connected to the aluminum container. The sealing of the containers is made with a butyl-aluminum tape that has been tested to ensure no leakage of radon

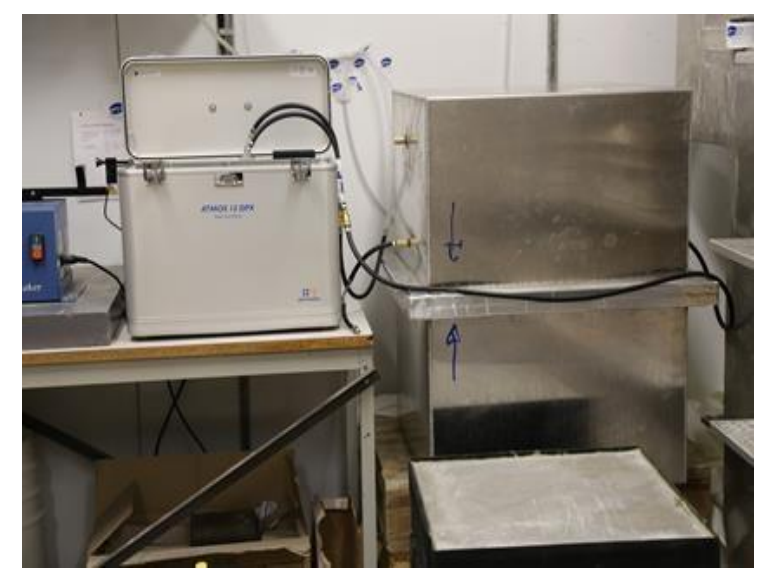

Figure (1b): The diffusion chamber (blackish) to the right of the aluminum container with a receiver (red arrow) and a source chamber (blue arrow) and a sample in between to measure the diffusion rate

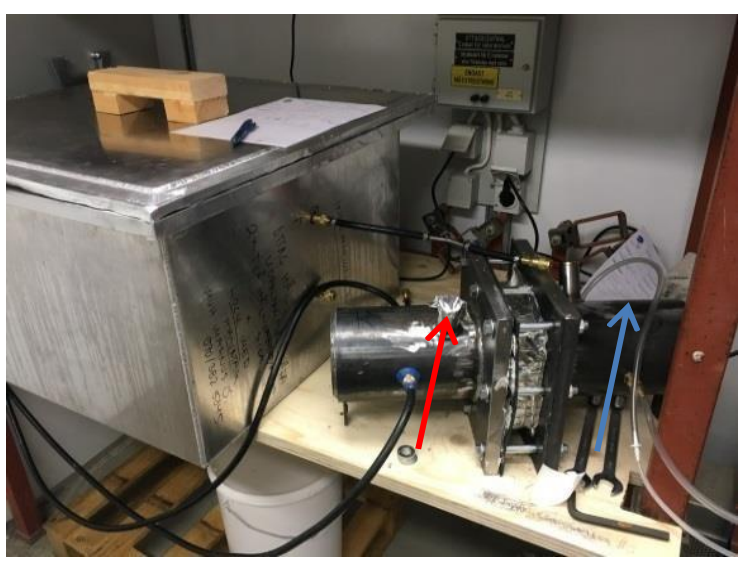

Diffusion measurements

Using Fick's first law of mass transfer a diffuse flow through a material under a steady state condition of a radon source concentration can be determined [36]. The principle makes use of a source and a receiver chamber with a sample of concrete in between (Figure 1b). Using a small uranium source within an enclosed chamber (source chamber) a secondary equilibrium will be achieved between $238 \mathrm{U}$ and its progenies within 8-10 days in the source chamber (steady state). Once a 
Dose M, Silfwerbrand J (2018) Supplementary cementitious materials and additives- Effective measures to hinder radon in concrete. J Adv Eng; 1(2): 107.

steady state in the source chamber is achieved, the receiver chamber can be flushed with nitrogen to have a very low initial radon concentration. The measurement of the radon diffusion coefficient is initiated immediately after the chamber has been flushed. The procedure is well described by Chauen \& Kumar [6]. In short, the permeability of the material is in part related to the porosity of the material $[4,6]$ and the porosity could be related to the diffusion of a gas through a material [6] according to:

$$
p=D / D_{e}
$$

where, $\mathrm{D}$ is the diffusion coefficient $\left(\mathrm{m} / \mathrm{s}^{2}\right)$ and De, the effective diffusion coefficient $\left(\mathrm{m}^{2} / \mathrm{s}\right)$.

The radon diffusion coefficient's can be expressed as the diffusion length (L) as to give a measure of how much radon that is exhaled before $50 \%$ of the radon decayed per unit distance $(\mathrm{m})$. Using the radon decay constant $(\lambda)$ the diffusion relates to the radon diffusion length (L) according to,

$$
L=\sqrt{\mathrm{D} / \lambda}
$$

\section{Assessments}

\section{Concrete recipes}

The concrete recipes contained identical constituents (aggregates, cement, water) where the only difference was (i) a contribution of different additives for three recipes and, (ii) partial replacement of the Ordinary Portland Cement (OPC) by different SCM's such as fly ashes, slag, micro-silica or a combination of both SCM's and an additive. All in all ten recipes were blended, including one recipe using only ordinary Portland cement as a reference. Five identical concrete cubes $(150 \times 150 \times$ $150 \mathrm{~mm}$ ) and five concrete prisms (75 $\times 75$ $\times 300 \mathrm{~mm}$ ) were cast for each recipe and after remolding the cubes and prisms were cured in a water bath for one month to reduce and prevent cracking. After one month, two of the concrete cubes were sawn to acquire plates with a thickness of $50 \mathrm{~mm}$ for diffusion measurements. One plate was randomly chosen as the test specimen. Three out of six prisms were cut in half as to have six specimens with a length of $150 \mathrm{~mm}$.

(Table 1): The different concrete recipes are listed below with different portions of SCM's and

\begin{tabular}{|c|c|c|c|c|c|c|c|c|}
\hline Recipe & Cement, & Fly ash, & $\begin{array}{l}\text { Fly ash, } \\
\text { microsite }\end{array}$ & Slag & $\begin{array}{l}\text { Mikrosilica, } \\
\text { grade } 940\end{array}$ & \multicolumn{3}{|c|}{ Additives } \\
\hline & $\begin{array}{c}30-60 \\
\mu \mathrm{m}\end{array}$ & $\begin{array}{c}10-50 \\
\mu \mathrm{m}\end{array}$ & $<10 \mu \mathrm{m}$ & $1-30 \mu \mathrm{m}$ & $0.15 \mu \mathrm{m}$ & A1 & A2 & A3 \\
\hline & $\begin{array}{c}\text { Portion } \\
(\%)\end{array}$ & $\begin{array}{c}\text { Portion } \\
(\%)\end{array}$ & $\begin{array}{c}\text { Portion } \\
(\%)\end{array}$ & $\begin{array}{c}\text { Portion } \\
(\%)\end{array}$ & Portion (\%) & & & \\
\hline 1 & 100 & & & & & & & \\
\hline 2 & 100 & & & & & $X$ & & \\
\hline 3 & 100 & & & & & & $X$ & \\
\hline 4 & 100 & & & & & & & $X$ \\
\hline 5 & 65 & 15 & 20 & & & & & \\
\hline 6 & 65 & & 35 & & & & & \\
\hline 7 & 35 & & & 65 & & & & \\
\hline 8 & 90 & & & & 10 & & & \\
\hline 9 & 65 & & & & 35 & & & \\
\hline 10 & 75 & & 15 & & 10 & & & \\
\hline
\end{tabular}
additives 
Dose M, Silfwerbrand J (2018) Supplementary cementitious materials and additives- Effective measures to hinder radon in concrete. J Adv Eng; 1(2): 107.

A standard CEM I $52.5 \mathrm{RH}$ (rapid hardening properties) from the Skövde cement factory was used as the reference binder. The component of air was set to approximately $1 \%$. A cement-content of $350 \mathrm{~kg} / \mathrm{m}^{3}$ was applied. The SCM's with pozzolanic properties such as the fly ash used originates from Germany and are composed of two different grain sizes (Table 1). The micro-silica (940) used originates from Elkem. The slag, also being a hydraulic binder, originates from Bremen. The bulk (liquid) additives come from different manufacturers. The recipes followed the recommendations of the manufacturers. The portion used was the recommended maximum dose of $\sim 2-3 \%$ (vol.) of the water content. Table 1 presents an overview of the recipes, different binder proportions and additives used. The additives (A1, A2, A3) are combinations of carboxylic acid groups, silanes or polysiloxanes Due to volumetric differences of the binders (different densities) a slight difference in the amount of crushed aggregates will occur per $\mathrm{m}^{3}$ of concrete. However, this small difference is considered negligible.

\section{Relative Humidity and measurement technique}

Measurements were made using equipment from Vaisala Oy named Vaisala $\mathrm{HM} 44$. The salts, $\mathrm{LiCl}$ and $\mathrm{K}_{2} \mathrm{SO}_{4}$, were chosen as internal control salts for calibration of the probes (11 and $98 \%$, respectively in $\mathrm{RH}$ at approximately $20^{\circ} \mathrm{C}$ ). Using calibration tables from Greenspan [7] an uncertainty less than $1.5 \%$ was calculated for the probes before the first measurements were initiated.

\section{Process of measurement}

The cast cubes and prisms were after one month of curing in water, immediately sawn and thereafter placed in plastic boxes. The bottom of the plastic boxes has a $5 \mathrm{~mm}$ layer of $\mathrm{NaCl}$ salt that is put in place by a hollow stiff plastic carpet. The stiff plastic carpet ensures that the salt is separated from the samples (Figure 2a). A circulation pump was connected by hoses to each plastic box with an inlet and outlet hose and circulated ten minutes every 24 hours. The procedure is maintained as to ensure a good circulation of the air within the box. The top of the plastic boxes had a lid, with two plastic tubes attached to the lids by epoxy glue and sealed with alumina tape (Figure $2 \mathrm{~b}$ ). The tubes were used as to measure the relative humidity of the air inside the box containing the samples. Probes were enclosed into the tubes and fixed in place at least 48 hours before a reading commenced.

The procedure to assess the relative humidity within the concrete was achieved by drilling holes at specific levels into the concrete cubes and prisms: in this investigation at $10 \mathrm{~mm}$ and $25 \mathrm{~mm}$ depth. Black plastic tubes (hollow inside) were inserted into the drilled holes of the concrete reference specimens for each recipe, and a sealing epoxy was added between outside of plastic tubes and the concrete to ensure no leakage of air. In (Figure 2a) the reference concrete samples with their inserted tubes are seen with the radon prisms and diffusion plates used for measurements. The measurements were conducted by inserting the probe inside the plastic tube and sealing it with a rubber gasket at the top (Figure 2b). The first measurements were made approximately 6 weeks after the concrete specimens were cast.

Figure (2a): The cut prisms and plates placed resting on the plastic grey hollow carpet. Small NaCl-cups are placed on a few samples to ensure an environment close to $75 \%$ RH within the full volume

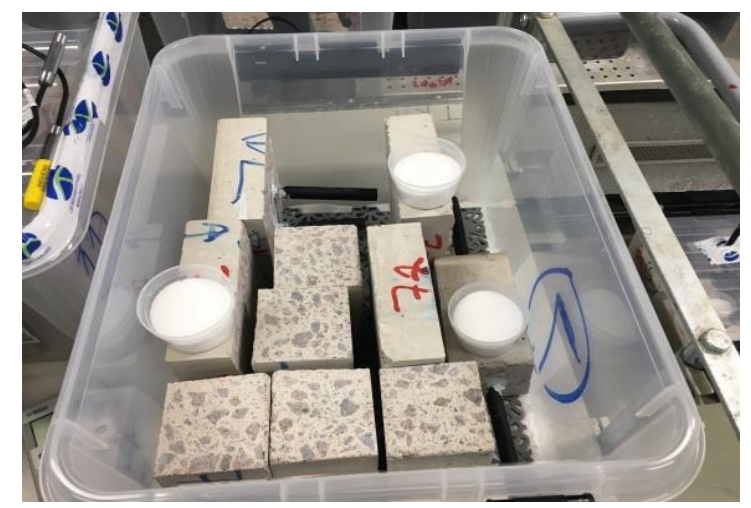

Figure (2b): The same sample with a lid on top enclosed by tape. The reading $5 \mathrm{~cm}$ 
Dose M, Silfwerbrand J (2018) Supplementary cementitious materials and additives- Effective measures to hinder radon in concrete. J Adv Eng; 1(2): 107.

below the top in the air shows $75.7 \%$ in $\mathrm{RH}$ using probe 10

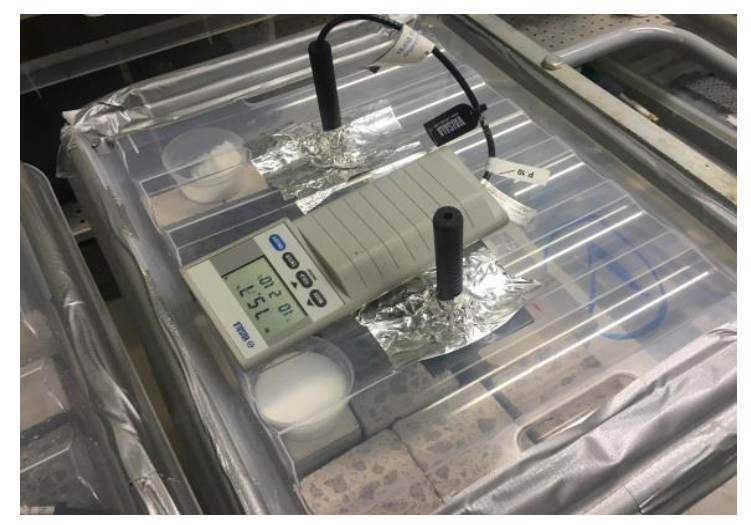

The samples enclosed in the plastic boxes were stored in a conditioning room with $85 \% \mathrm{RH}$ and a temperature of $23^{\circ}$ Celsius. The salts, in the boxes were during the dry out period monitored as not to be fully saturated. In two cases some extra salt had to be added to the samples. A dry out period of at least four months was calculated, before approximately an $\mathrm{RH}$ of $75 \%$ could be reached at a depth of $10 \mathrm{~mm}$. Approximately five to six months after the concrete were cast the reference specimens had an RH of $75 \%$ at $10 \mathrm{~mm}$ depth. Hence, the humidity within the specimens at 10 $\mathrm{mm}$ depth, were in level with the environment produced by the $\mathrm{NaCl}$ salts inside the boxes, and the first measurements could be commenced. Regarding measurements of radon gas at least four prisms were used to measure the exhalation rate of the different recipes (Figure 3). All sides, except the top, were sealed using an alumina tape with a $2 \mathrm{~mm}$ thick butyl layer inside.

\section{Results}

\section{Radon gas measurements}

(Figure 3) shows the results of the radon gas measurements at a $\mathrm{RH}$ of $75 \%$ at $10 \mathrm{~mm}$ depth within the concrete samples. The sample numbers can be correlated to the recipes presented in (Table 1).

Figure (3): The radon exhalation rate of each concrete recipe investigated

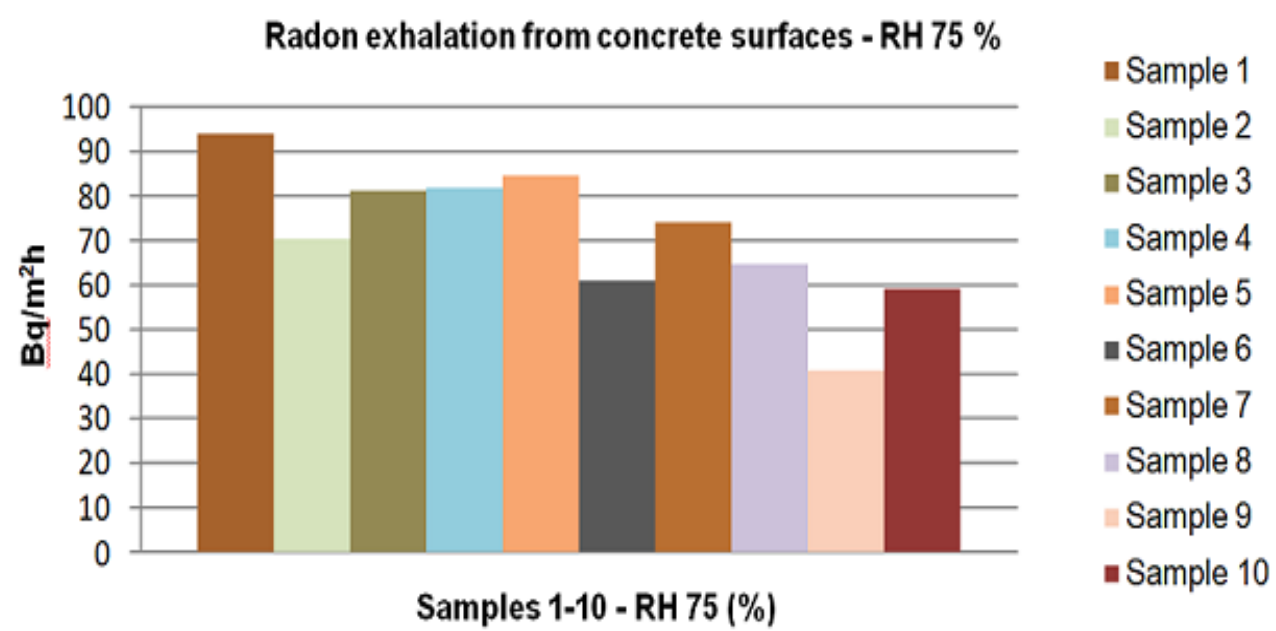

The radon diffusion coefficients and radon diffusion lengths

(Figure 4) presents the calculated radon gas diffusion lengths. The corrected data include a subtraction of the radon gas build up from each sample in the receiver chamber without any uranium source in the source chamber. (Table 2) presents the diffusion coefficients. 
Dose M, Silfwerbrand J (2018) Supplementary cementitious materials and additives- Effective measures to hinder radon in concrete. J Adv Eng; 1(2): 107.

Figure (4): Calculated radon gas diffusion lengths (L) of each concrete recipe

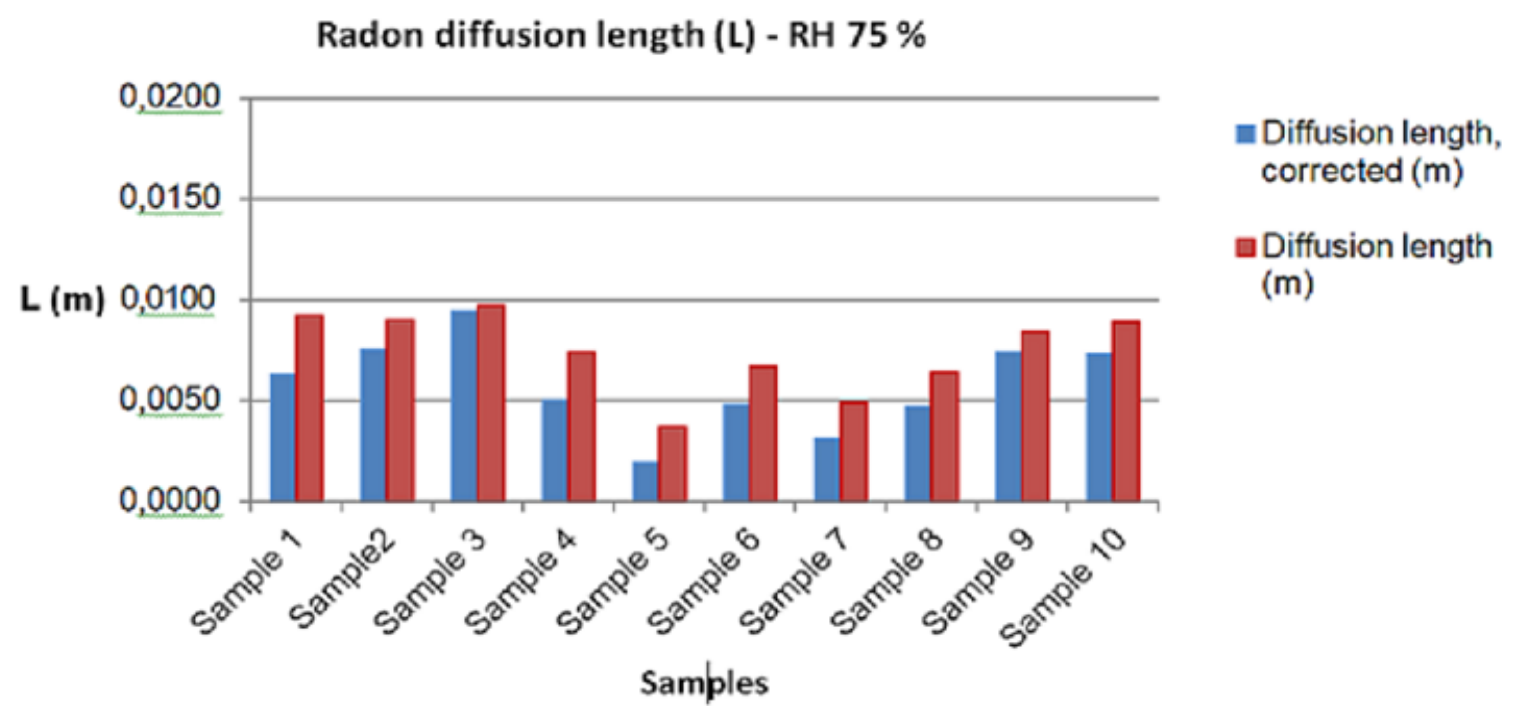

Table (2): The calculated diffusion lengths and diffusion coefficients

\begin{tabular}{|c|c|c|c|c|}
\hline Sample & $\begin{array}{c}\text { Diffusion } \\
\text { length (m) }\end{array}$ & $\begin{array}{c}\text { Diffusion length, } \\
\text { corrected }(\mathbf{m})\end{array}$ & $\begin{array}{c}\text { Bulk radon } \\
\text { diffusion } \\
\text { coefficient } \\
\left(\mathbf{m}^{2} / \mathbf{s}\right)\end{array}$ & $\begin{array}{c}\text { Bulk radon diffusion } \\
\text { coefficient }\left(\mathbf{m}^{2} / \mathbf{s}\right) \text {, corrected }\end{array}$ \\
\hline Sample 1 & 0,0092 & 0,0063 & $1,78 \times 10^{-10}$ & $8,33 \times 10^{-11}$ \\
\hline Sample 2 & 0,0090 & 0,0075 & $1,70 \times 10^{-10}$ & $1,18 \times 10^{-10}$ \\
\hline Sample 3 & 0,0097 & 0,0094 & $1,98 \times 10^{-10}$ & $1,86 \times 10^{-10}$ \\
\hline Sample 4 & 0,0074 & 0,0050 & $1,15 \times 10^{-10}$ & $5,25 \times 10^{-11}$ \\
\hline Sample 5 & 0,0037 & 0,0019 & $2,87 \times 10^{-11}$ & $7,58 \times 10^{-12}$ \\
\hline Sample 6 & 0,0067 & 0,0048 & $9,43 \times 10^{-11}$ & $4,84 \times 10^{-11}$ \\
\hline Sample 7 & 0,0049 & 0,0031 & $5,04 \times 10^{-11}$ & $2,02 \times 10^{-11}$ \\
\hline Sample 8 & 0,0064 & 0,0047 & $8,60 \times 10^{-11}$ & $4,64 \times 10^{-11}$ \\
\hline Sample 9 & 0,0084 & 0,0074 & $1,48 \times 10^{-10}$ & $1,15 \times 10^{-10}$ \\
\hline Sample & 0,0089 & 0,0073 & $1,66 \times 10^{-10}$ & $1,12 \times 10^{-10}$ \\
\hline 10 & & &
\end{tabular}

\section{Discussion}

It is noticeable from the radon gas exhalation measurements that the input of additives or SCM'S may have a fairly strong impact on the radon gas exhalation rate. In one case a reduction of more than $50 \%$ is noticeable (recipe 9). For fly ash a reduction of 30-35\% could be shown compared to the reference concrete. [8] Reported that an addition of fly ash in general reduces the general pore size. $[9,10]$ reported similar conclusions where the use of fly ash and micro silica as a SCM reduced the total pore volume and also an overall smaller pore size compared to a reference concrete. A decrease of the average pore size reduces the inter-connectivity between the pores and the permeability as a result. The current study seemingly supports this concept. The liquid additives are bulk additives that contain alkali-metal ions 
Dose M, Silfwerbrand J (2018) Supplementary cementitious materials and additives- Effective measures to hinder radon in concrete. J Adv Eng; 1(2): 107.

(sodium or potassium) in combination with carboxylic acid groups and polysiloxane constituents. The initial key being to create a covalent bond of an inorganic substance to an organic. In brief, the bulk additive is added to the water, initiating a three stage process; (i) hydrolysis, followed by (ii) condensation and (iii) bonding [11]. This bonding with cement, or C-S-H or aggregate leads in turn to a reduced free transport of water and reduced breathability [11] and hence also a reduced water absorption [12, 13].

However, the pore structure is still open, but with a lower diffusion coefficient [11]. Also, the overall low diffusion coefficients and their radon gas diffusion lengths of the concrete recipes are of interest. In general half of the radon produced has decayed within the first 10 $\mathrm{mm}$ of the concrete plates. Meaning, almost all radon, $\sim 90 \%$ are generated within the first $30 \mathrm{~mm}$ of the concrete cubes. The different SCM's used contain different contents of uranium. This has not yet been evaluated but may in part influence the results. A final calculation of each recipes emanation factor in response to uranium content $(\mathrm{Bq} / \mathrm{kg})$ should be included in a finalized study. Finally, the correlation between the radon gas exhalation of the concrete recipes and its respective diffusion length is fairly meager, but overall, the figures show that an addition of additive or SCM's in general lower the exhalation rate of the concrete. In a few cases an effect of minor cracks that would increase the diffusion drastically for some specimens/sample may also be an influence.

\section{Concluding Remarks}

In the current study it has been demonstrated a reduction of $10-55 \%$ of the radon gas exhalation rate from some concrete recipes using a liquid additive or a SCM (fly ash) at relative humidity $\sim 75 \%$. The calculated diffusion lengths of the radon gas are all less than $10 \mathrm{~mm}$ in the study. This means that vast majority of the radon will be generated at the most superficial $30 \mathrm{~mm}$ of the surface of a dense concrete. The reduction of the radon exhalation rates at the end reduces the effective dose absorbed by the human body. Using guidelines of ICRP [14], the reduction of the radon exhalation rate using additives or SCM's in this study, showed in some cases a reduction of 30-35\%. This would be equivalent to a reduced effective dose of $1.5-2 \mathrm{mSv}$ per year compared to the reference concrete. This is in relation to the reference value of the normal concrete specimen investigated and relates to the European reference room [15] where all walls, tile and floor are made of concrete. The use of SCM's as part of the binder and an alternative to OPC also serves a mean to lower the overall use of Portland cement worldwide. This at the end generates a positive impact from an environmental aspect.

\section{Acknowledgements}

Special thanks to the Swedish Consortium for Financing Fundamental Research in the Concrete Area who has partly funded the research in the concrete area. Special thanks also to my supervising group and my colleagues at RISE CBI aiding in the casting procedure.

\section{References}

1. World Health Organization (2009) WHO Handbook on Indoor Radon: a Public Health Perspective. World Health Organization, Geneva; Pp: 110.

2. ISO 11665-7 (2012) Measurement of radioactivity in the environment - Air: radon-222 - Part 7: Accumulation method for estimating surface exhalation rate. International Standard (ISO), 1 Edn, Geneva, Switzerland; Pp: 23.

3. Kovler K (2006) Radon exhalation of hardening concrete: monitoring cement hydration and prediction of radon concentration in construction site. Journal of Environmental Radioactivity; 86(3): 354-366. 
Dose M, Silfwerbrand J (2018) Supplementary cementitious materials and additives- Effective measures to hinder radon in concrete. J Adv Eng; 1(2): 107.

4. Cozmuta I, van der Graaf ER (2001) Methods for mearuing diffusion coefficients of radon in building materials, The Science of the Total Environment; 272(1-3): 323-335.

5. Chauhan RP, Kumar A (2013) Radon resistant potential of concrete manufactured using ordinary portland cement blended with rice husk ash. Atmospheric Environment; 81: 413420.

6. Chauhan RP, Kumar A (2013) Study of radon transport modified with silica fume. Radiation Measurements; 59: 5965.

7. Greenspan L (1977) Humidity Fixed Points of Binary Saturated Aqueous Solutions. Journal of Research of the National Bureau of Standards- A Physics and Chemistry; 81A(1): 89-95.

8. De Jong P, van Dijk W, van Hulst JGA, et al. (1996) The effect of the composition and production process of concrete on the 222Rn exhalation rate. Environmental International; 22: 287293.

9. Taylor-Lange SC, Juenger MCG, Siegel JA (2014) Radon emanation fractions from concretes contacting fly ash and metakaolin. Sci Total Environ; 466-467: 1060-1065.

10. Setina J, Gabrene A, Juhnevica I (2013) Effect of pozzolanic additives on structure and chemical durability of concrete. Procedia Engineering; 57: 1005-1012.
11. Roos M, König F, Stadtmüller S, et al. (2008) Evolution of Silicone Based Water Repellents for Modern Building Protection. 5th International Conference on Water Repellent Treatment of Building Materials, Bruxelles, Aedificatio Publishers; Pp: 3-16.

12. Selander A, Davant N, Malaga K (2014) hydrophobic shotcrete - a method to waterproof tunnels. Hydrophobe VII 7th International Conference on Water Repellent Treatment and Protective Surface Technology for Building Materials. Lisbon, Portugal; Pp: 67-75.

13. Spaeth V, Delplancke-Ogletree MP, Lecomte JP (2008) Hydration Process and Microstructure Development of Integral Water Repellent Cement Based Materials. 5th International Conference on Water Repellent Treatment of Building Materials, Bruxelles, Aedificatio Publishers; Pp: 245-254.

14. Tirmarche M, Harrison JD, Laurier D, et al. (2010) ICRP Lung Cancer Risk from Radon and Progeny and Statement on Radon. ICRP Publication 115 Ann ICRP; 40(1).

15. CEN/TR 17113. (2017) Construction products - Assessment of release of dangerous substances - Radiation from construction products - Dose assessment of emitted gamma radiation. European committee for standardisation, CEN; Pp: 47. 